\title{
Empirical Spectral Amplification Function for a Reference Site Near Keddara Dam in Algeria using Strong Motion Data.
}

Faouzi Gherboudj ( $\sim$ fgherboudj@cgs-dz.org )

Centre National de Recherche Appliquée en Génie Parasismique: Centre National de Recherche Appliquee en Genie Parasismique https://orcid.org/0000-0003-1555-8907

\section{Toufiq Ouzandja}

Centre National de Recherche Appliquée en Génie Parasismique: Centre National de Recherche Appliquee en Genie Parasismique

\section{Rabah Bensalem}

Centre National de Recherche Appliquée en Génie Parasismique: Centre National de Recherche Appliquee en Genie Parasismique

\section{Research Article}

Keywords: empirical amplification function, strong motion, GMPE, spectral ratio

Posted Date: July 24th, 2021

DOl: https://doi.org/10.21203/rs.3.rs-728351/v1

License: (c) (1) This work is licensed under a Creative Commons Attribution 4.0 International License. Read Full License 


\title{
Empirical spectral amplification functions for a reference site near Keddara dam in Algeria using strong motion data.
}

\author{
Faouzi Gherboudj ${ }^{1}$ Toufiq Ouzandja $^{1}$ Rabah Bensalem ${ }^{1}$
}

Abstract

This paper deals with empirical spectral amplification function for a reference site (STK) near Keddara dam in Algeria using local strong ground motion of earthquakes of magnitudes Mw 4.0-6.8. Amplification function is obtained as the 5\% damped mean spectral ratio of surface observed and the rock predicted ground motions and it is compared to the ambient vibration HVSR which shows a good agreement in terms of fundamental frequency and curve tendency.

In addition, recorded ground motions are compared to surface predicted motion with modified GMPE, the site term of the local ground motion prediction equation is adjusted based on the obtained amplification function of the free field STK site. Examples of the M 6.8, M5.4 and M4.7 earthquakes show clearly the advantage of using the adjusted Ground Motion Prediction Equations (GMPE) for predicting surface ground motion. Site effect characterization and the adjusted GMPE presented in this study provide the basis elements toward partially non ergodic site specificProbabilistic seismic hazard assessment (PSHA) application based on local strong motion data in Algeria.

Keywords: empirical amplification function, strong motion, GMPE, spectral ratio 


\section{Introduction}

Site effect evaluation is the last step in probabilistic and deterministic seismic hazard analysis to define seismic loads for building seismic design. In general, amplitudes of seismic waves crossing superficial layers of soil tend to amplify (de-amplify) according to the local geology of the site and therefore poor knowledge or bad modeling can lead to an overestimation or underestimation of surface seismic loads. Generally, amplification factors are defined in design codes to estimate such effect (Anastasiadis et al. , 2014), however, an in depth study of site effect combined with probabilistic seismic hazard analysis should be conducted for important projects such as hospitals, dams or nuclear power plants (Vecchietti ;2019; Stewart; 2019).

Seismic wave propagation is considered in PSHA through GMPE using both the mean value of the predicted ground motion and its variability (sigma) to estimate the exceedance probability of a given hazard level. Site effect is integrated implicitly in GMPE mostly as a function of shear wave velocity Vs30 following the ergodic assumption. In fact, the mean value of ground motion and its variability estimated by GMPE is based on strong motion data recorded over space and it will be assumed as an estimate of the mean value for a specific site over time. Partially non-ergodic PSHA in site specific study however seeks to reduce the aleatory variability (sigma) related to site effect by adjusting the predicted median ground motion with respect to the site effect using the mean amplification function for the specific site (Atkinson, 2006, Rodriguez et al. 2014, Stewart et al. 2017).

Numerical approach such as 1D linear equivalent method is largely used in practice to conduct ground response analyses in spite of its limitations related to soil model and lack of information about materials behavior. Empirical approach could be a better alternative which is based on strong motion data using reference or non-reference site method (Stewart, PEER 2014). In fact, amplification function could be calculated by means of spectral ratio between the observed ground motions from two near soft and rock sites (reference site approaches, Borcherdt and Gibbs 1970; Borcherdt and Glassmoyer 1994) or between observed and mean predicted ground motion (non-reference site approach, Stewart et al. 2003). Si al. (2010) for example used the later approach to remove site effect from strong motion data in studying the hanging wall effect of the 1994 Northridge earthquake, also, Ibrahim et al. (2014) used strong motion records to derive empirical spectral amplification functions for 75 sites in the Iwate-Miyagi and Niigata regions, the relatively large data available from a dense array in Japan allowed the reduction of error in each site by summing and averaging the obtained ratio. In addition, non-reference site approach is largely used to determine the site amplification in the process of developing GMPE (Atkinson et al. 2015).

Algerian context is characterized by weak to moderate seismicity, the application of empirical method to derive amplification function depends on the amount of data available from the strong motion network managed by research center of earthquake engineering (CGS) covering all the north of Algeria. Several earthquakes having magnitude between 4 and 6.8 have been recorded in the last decades which allow recently the elaboration of local ground motion prediction equation by Laouami et al. (2018). Site effect is considered in this equation using H/V method which conducted to three soil classes (rock, ferm and soft) in terms of $\mathrm{V}_{S 30}$.

In this study, we propose to investigate the site effect by empirical approach of a free field site (STK) near Kaddara dam in Boumerdes region (figure 1) using the available strong motion data recorded by accelerometers type ETNA installed on this site since more than 20 years. In fact, STK is considered as reference site and assumed as a rock site since it is located on the metamorphic basement formed by Micaschists and Gneis of Paleozoic. Strong motion records of the 2003 Boumerdes earthquake recorded at this site were largely used in seismic risk analysis as the input motion at the soil profiles or structures (eg. Jica 2006). Therefore it is an important task to well identify this site in terms of amplification function allowing bettering characterizing strong motion recorded on this site. 


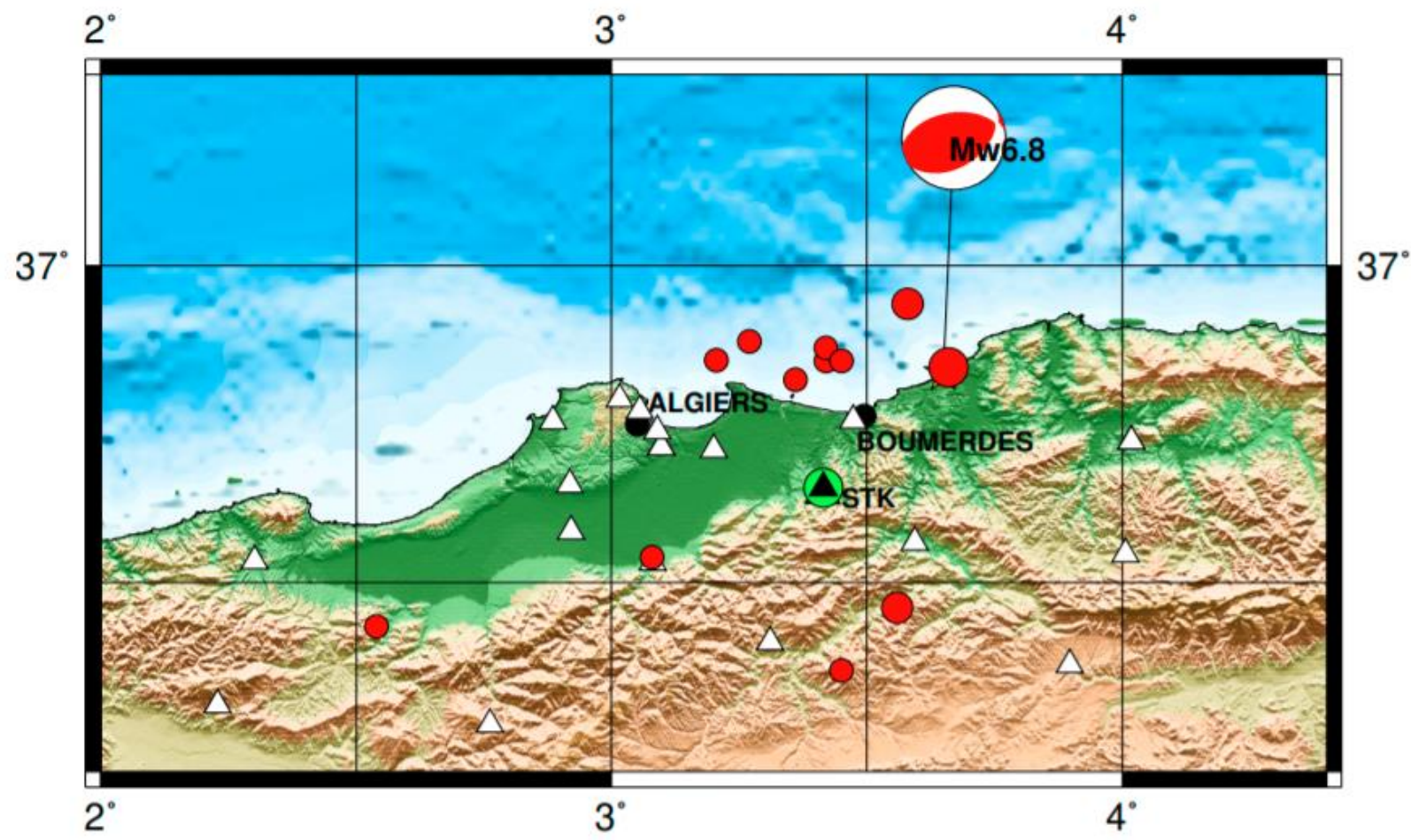

Figure 1 Sketch map that illustrates STK site near the Kaddara dam location (black tringle) and events used in this study (red circles, size of each circle is function of its magnitude) recorded in stations indicted by white triangles.

\section{Strong motion data}

Site analysis with empirical method requires strong motion data recorded close to the considede site. Therefore, a relatively large number of records are available for this site provided by Algerian seismic network (www.cgs.dz.org). It corresponds to earthquakes with magnitude $>4.0$ and hypocentral distance less than $200 \mathrm{~km}$, only events recorded by at least 3 stations are considered in this analysis (including the considered station (STK)). A total of 23 records related to 12 earthquakes are used in this study (table 1), they have been recorded by ETNA stations installed in this site. All selected events have been occurred between 2003 and 2020 such as the 2003 M6.8 Boumerdes earthquake (Bounif et al. 2004) and its aftershoks, 2014 M5.5 Algiers earthquake (Benfedda et al. 2017), 2013 M5.0 Hammam melouane earthquake (Yelles et al. 2017) and the 2016 M5.4 Mihoub earthquake (Khelif et al. 2018). Moment magnitude is used in the computation of the predicted ground motion together with hypocentral distance R_hypo calculated directly from information about localization and depth. 
Table 1 List of events used in this study (Mw>4.0)

\begin{tabular}{|c|c|c|c|c|}
\hline Date & Time & Mw & Depth & Location \\
\hline \multirow{2}{*}{$21 / 05 / 2003$} & \multirow{2}{*}{$18: 44: 21$} & \multirow{2}{*}{6.8} & \multirow{2}{*}{12} & $36.98 \mathrm{~N}$ \\
\hline & & & & $3.36 \mathrm{E}$ \\
\hline \multirow{2}{*}{$27 / 05 / 2003$} & \multirow{2}{*}{$17: 11: 29$} & \multirow{2}{*}{5.7} & \multirow{2}{*}{8} & $36.939 \mathrm{~N}$ \\
\hline & & & & $3.578 \mathrm{E}$ \\
\hline \multirow{2}{*}{$28 / 05 / 2003$} & \multirow{2}{*}{ 06:58:41 } & \multirow{2}{*}{5} & \multirow{2}{*}{10} & $36.88 \mathrm{~N}$ \\
\hline & & & & $3.27 \mathrm{E}$ \\
\hline \multirow{2}{*}{$29 / 05 / 2003$} & \multirow{2}{*}{ 02:15:02 } & \multirow{2}{*}{4.9} & \multirow{2}{*}{10} & $36.82 \mathrm{~N}$ \\
\hline & & & & $3.36 \mathrm{E}$ \\
\hline \multirow{2}{*}{$10 / 1 / 2004$} & \multirow{2}{*}{$18: 38: 15$} & \multirow{2}{*}{4.7} & \multirow{2}{*}{10} & $36.9898 \mathrm{~N}$ \\
\hline & & & & $3.3715 \mathrm{E}$ \\
\hline \multirow{2}{*}{$1 / 12 / 2004$} & \multirow{2}{*}{$18: 42: 49$} & \multirow{2}{*}{4.5} & \multirow{2}{*}{10} & $36.85 \mathrm{~N}$ \\
\hline & & & & $3.45 \mathrm{E}$ \\
\hline \multirow{2}{*}{$5 / 12 / 2004$} & \multirow{2}{*}{ 08:30:59 } & \multirow{2}{*}{4.4} & \multirow{2}{*}{10} & $36.92 \mathrm{~N}$ \\
\hline & & & & $3.38 \mathrm{E}$ \\
\hline \multirow{2}{*}{$1 / 2 / 2008$} & \multirow{2}{*}{$07: 33: 40$} & \multirow{2}{*}{4.6} & \multirow{2}{*}{10} & $36.825 \mathrm{~N}$ \\
\hline & & & & $3.473 \mathrm{E}$ \\
\hline \multirow{2}{*}{$22 / 2 / 2014$} & \multirow{2}{*}{ 19:30:15 } & 42 & 142 & $36.809 \mathrm{~N}$ \\
\hline & & 4.3 & 14.3 & $3.662 \mathrm{E}$ \\
\hline $1 / 8 / 2014$ & $04 \cdot 11 \cdot 16$ & 54 & 10 & $36.856 \mathrm{~N}$ \\
\hline $1 / 8 / 2014$ & 04.11 .10 & 5.4 & 10 & $3.181 \mathrm{E}$ \\
\hline & & & & $36.46 \mathrm{E}$ \\
\hline $28 / 05 / 2016$ & $00: 53: 17$ & 5.4 & 10 & $3.56 \mathrm{~N}$ \\
\hline & & & & $36.54 \mathrm{~N}$ \\
\hline $10 / 02 / 2016$ & 02:28:20 & 4.6 & 10 & $3.08 \mathrm{E}$ \\
\hline
\end{tabular}

\section{Methodology of spectral ratio using empirical method}

The spectral amplification function is computed as the ratio between the observed 5\% surface response spectra and the predicted rock response spectra by GMPE (Stewart et al. 2017). Earthquake records in vicinity of the target site are used together with ground motion prediction equation (GMPE). It is explained as the residual $\left(R_{i j}\right)$ of the surface spectrum with respect to GMPE as:

$R_{i j}=\ln \left(z_{i j}\right)-\left(\mu_{\ln z}\right)_{i j}$

$z_{i j}:$ is a measure of intensity of event $i$ on the target site $j$ 
The residues in Eq. (1) contain effects relating to the event term $i\left(\eta_{E, i}\right.$ : Between event residual), which should be removed to evaluate the within event residual $\left(\delta \mathrm{W}_{\mathrm{ij}}\right)$, it can be obtained as follow (Baltay, et al. 2017, Sahakian et al. 2018):

$\delta \mathrm{W}_{\mathrm{ij}}=R_{i j}-\mathrm{\eta}_{E, i}$

we calculated the between event effect term $\eta_{E, i}$ by a simple average of the recording motion of all $N_{i}$ events with respect to the predicted motions by the GMPE equation as proposed by Stewart et al. 2017.

$\eta_{E, i}=\frac{1}{N_{i}} \sum_{j=1}^{N_{i}} R_{i j}$

Afterwards, the component of the site term $\eta_{S j}$ can be determined approximately by averaging of the within event residual recorded at a site $j$

$\eta_{S j}=\frac{1}{N_{j}} \sum_{i=1}^{N} \delta \mathrm{W}_{i j}$

$N_{j}$ is the number of records on this site.

Then, regionally adjusted GMPEs were used to assess the response of the non-ergodic site to the specific site. According to Stewart et al. (2017), the average site amplification is represented through on-site recordings of regional GMPEs. More precisely, the estimate of the linear response of the site is the sum of the site term $\eta_{S j}$ on the site in question and the ergodic site term for such a Vs30 (Eq 5)

$\mathrm{F}_{S, i j}=F_{S, i}\left(V_{S 30}\right)+\eta_{S j}$ 


\section{Results and discussion}

Figure 2 and 3 show the empirical amplification function computed as the ratio between observed and predicted rock's spectral ground motion using two strong motion prediction equation, of Laouami et al. (2018) and Boore et al. (2014) to calculte ground motion with Vs $30=800 \mathrm{~m} / \mathrm{s}$. The solide line indicates the mean value with $95 \%$ confidence intervals. Both equations give a comparative function, however, using equation of Boore (2014) improve the precision in terms of dispersion in short periods. Amplification function is compared with $H / V$ curve in figure 4 shows a good aggrements in terms of curve tendency and fondamental frequency.

Amplification function AF_2500 with respect to bedrock of Vs30 $=2500 \mathrm{~m} / \mathrm{s}$ is shown in figure 5, we find that for long periods, amplification factor is equal to unity showing high shear wave velocity $(>800 \mathrm{~m} / \mathrm{s})$ of the rock soil under the surface layer. It is compared to $\mathrm{AF} \_800$ in figure 6 which shows a clear difference for periods $>0.1 \mathrm{~s}$. Therefore, considering the soil as a reference soil having Vs30 $=800 \mathrm{~m} / \mathrm{s}$ tends to underestimate the surface ground motion records for periods $>0.1 \mathrm{~s}$. This result is to be considered when using strong motion records at this site as an input motion for other soil profiles. A correction factor is to be introduced to include amplification from H_2500 (depth of layer of Vs30=2500 m/s) and $\mathrm{H} \_800(\mathrm{Vs} 30=800 \mathrm{~m} / \mathrm{s}$ ). The amplification function obtained here could be used as a correction factor for response spectra.

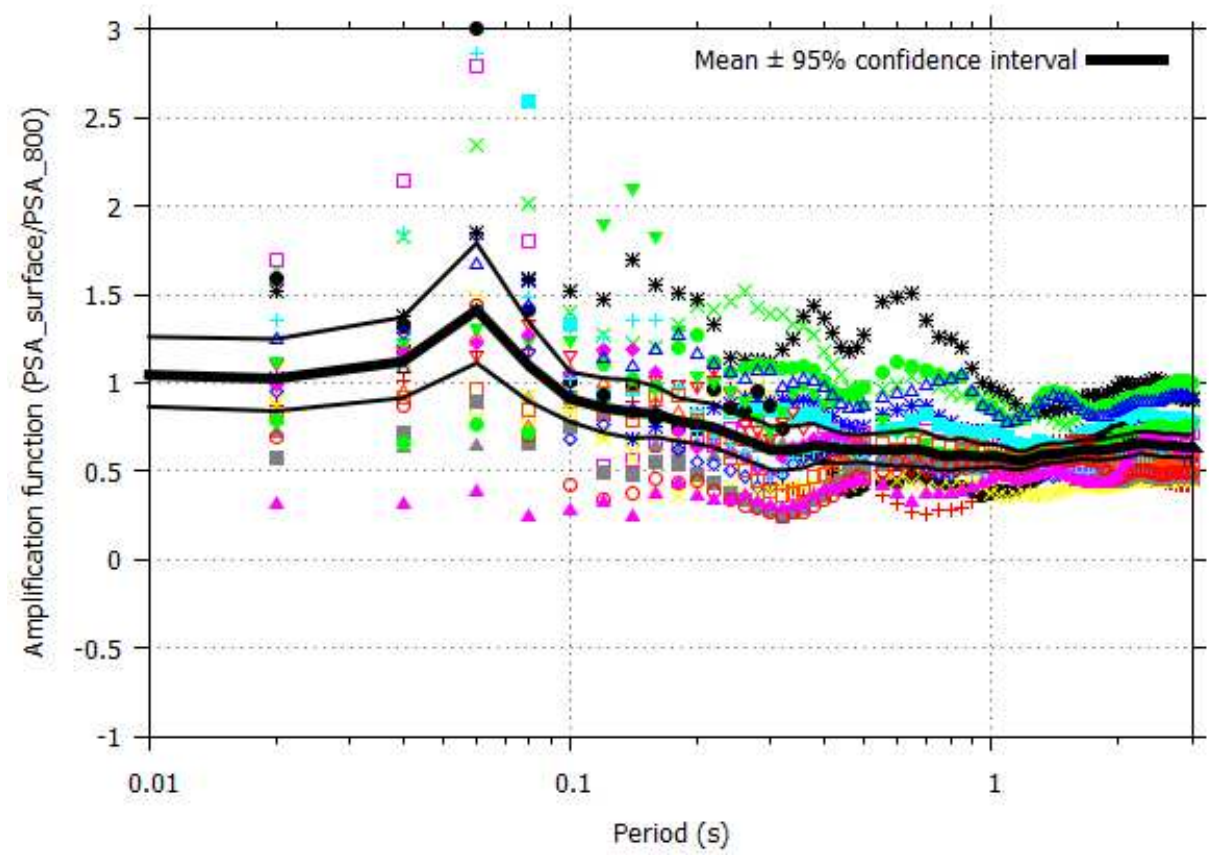

Figure 2 Empirical amplification function using the GMPE of Laouami et al. (2018) point lines indicate spectral ration for each event and solid line indicates the mean value. 


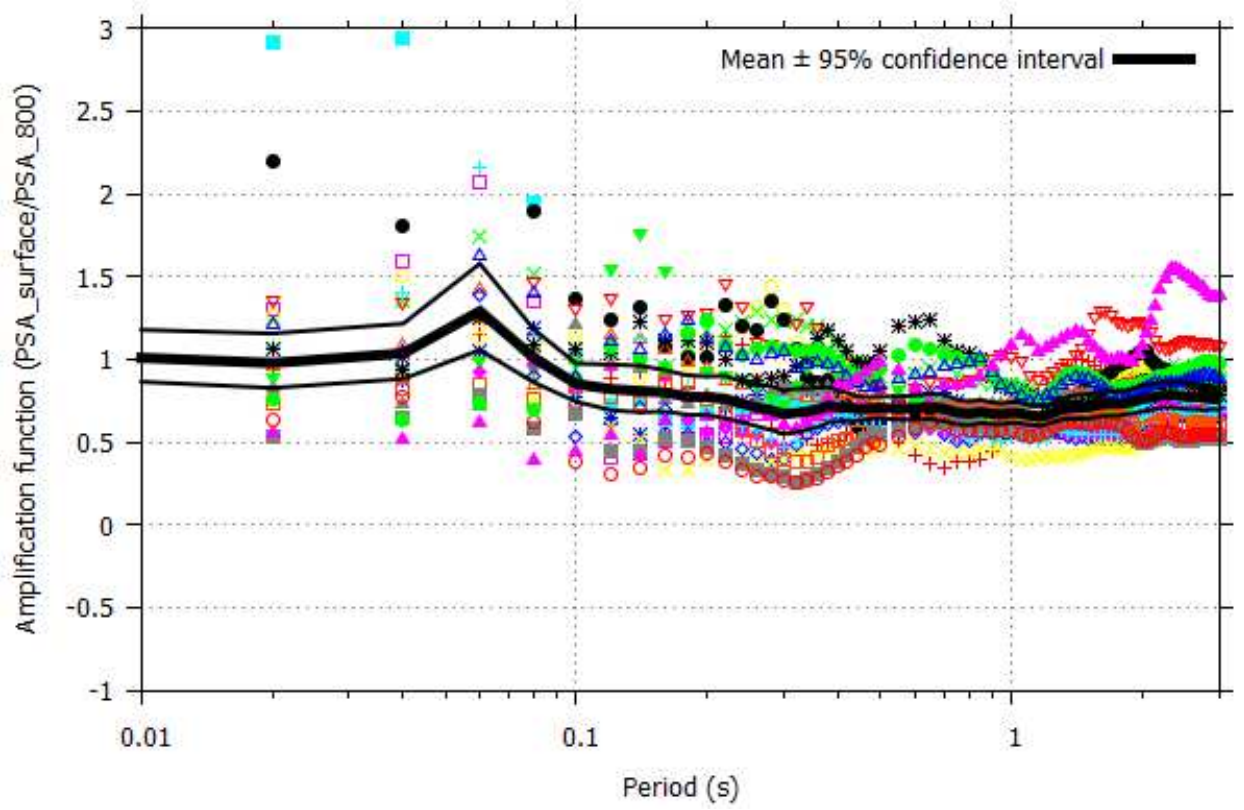

Figure 3 Empirical amplification function using the GMPE of Boore et al. (2014)

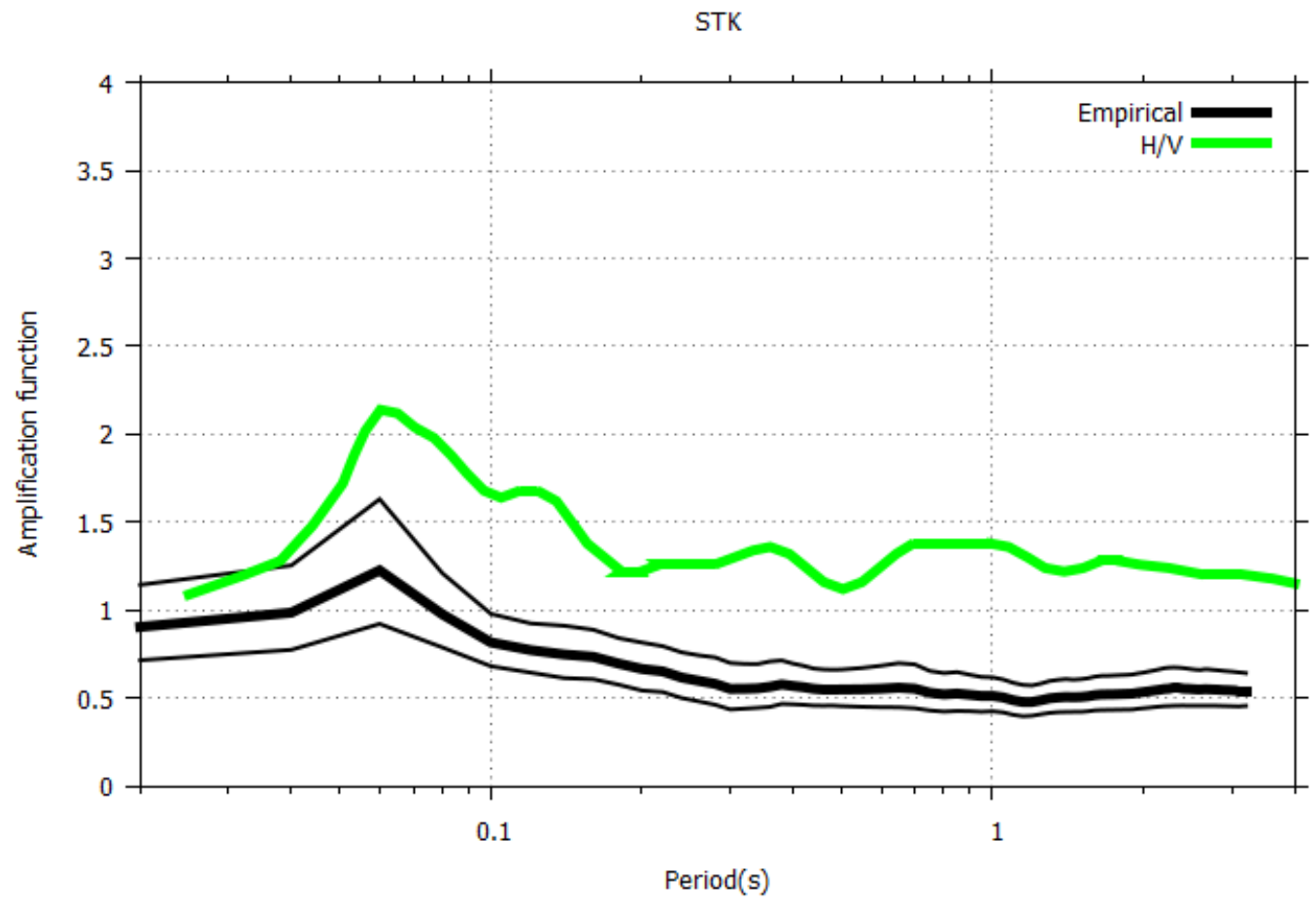

Figure 4 Empirical amplification function (Vs 30=800 m/s) compared to the HVSR Ambient vibration. 


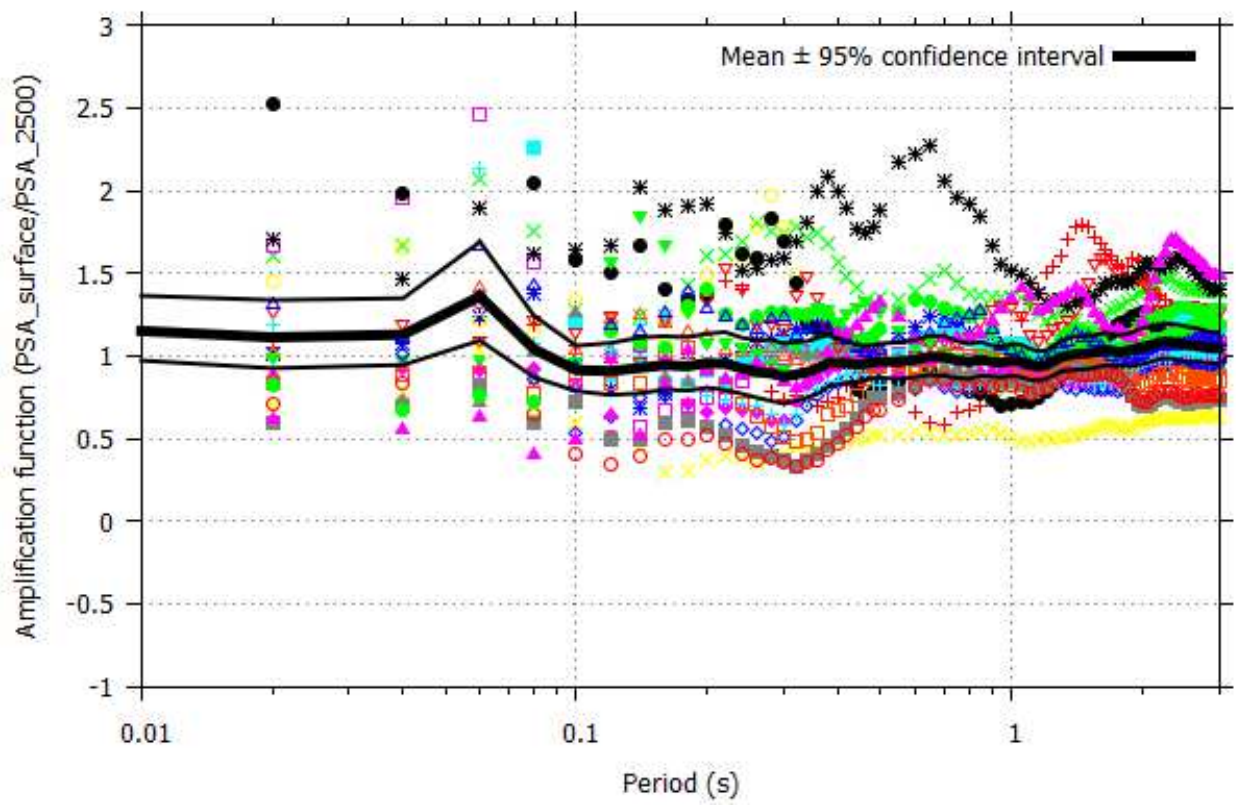

Figure 5 Empirical amplification function (Vs 30=2500 m/s) compared to the HVSR Ambient vibration.

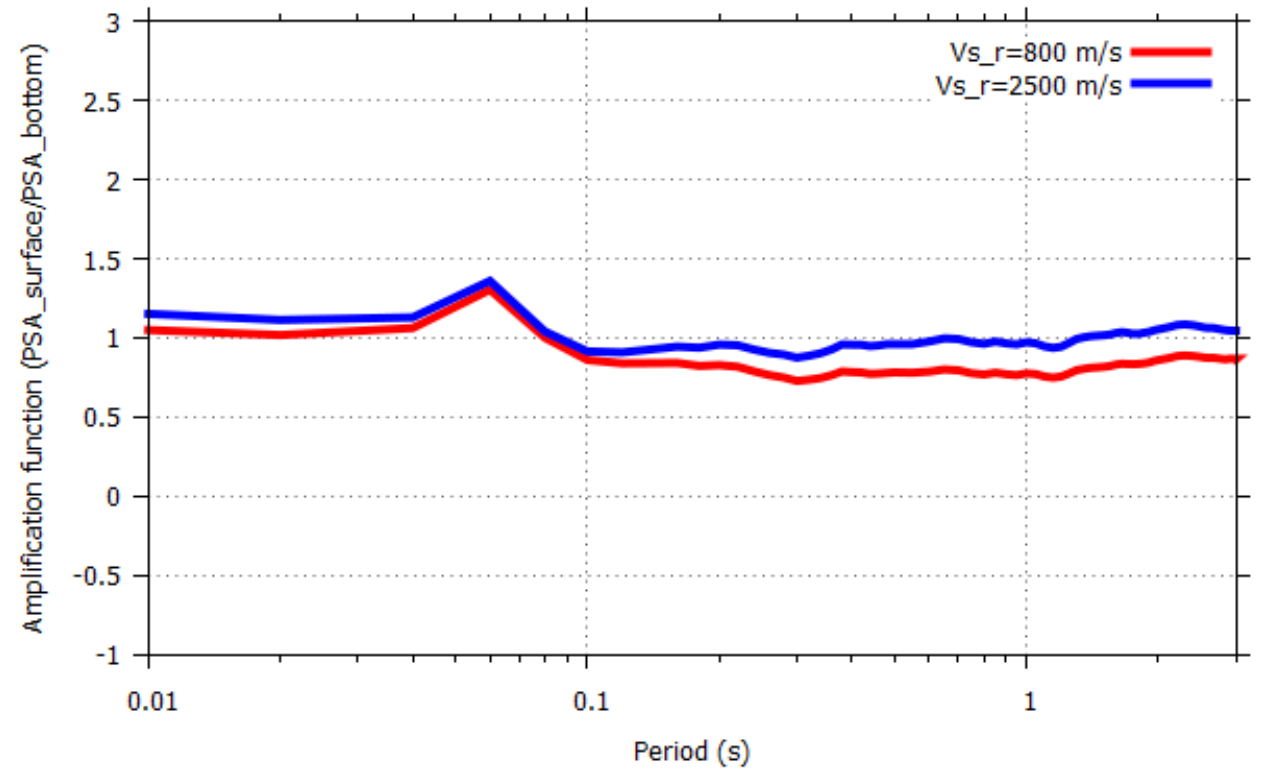

Figure 6 Mean empirical amplification function considering two bedrock shear wave velocity, $800 \mathrm{~m} / \mathrm{s}$ and $2500 \mathrm{~m} / \mathrm{s}$

The surface observed and predicted ground motions are also compared here to check the predictability of surface ground motion using local ground motion equation (Laouami et al. 2018) which it is adjusted with respect to site term.

The site term in the adjusted GMPE is shawon in equation (05) and it can be rewritten as follow:

$F s=F s(800)+A F(f)$ 
$F s(800)$ With Vs30 $=800 \mathrm{~m} / \mathrm{s}$ is computed from the originally GMPE site factor.

$\operatorname{AF}(f)$ is the empirical amplification function obtained for this site (Figure 2).

Three event are used here as example, the $2003 \mathrm{Mw}$ 6.8, 2004 M4.7 and the 2014 M 5.5. Those events were recorded by more than five stations.

Amplification function is computed by empirical method. We exclude records of each event from data used to compute the between event terms (Eq 3) and the amplification function (Eq 4) in order to avoid any influence of records in this site on the final surface ground motion predicted.

Figure 7, 8 and 9 show results in term of surface ground motions. The use of the adjusted GMPE improves clearly the prediction of ground motion with respect to the observed motion especially in periods greater than $0.1 \mathrm{~s}$.

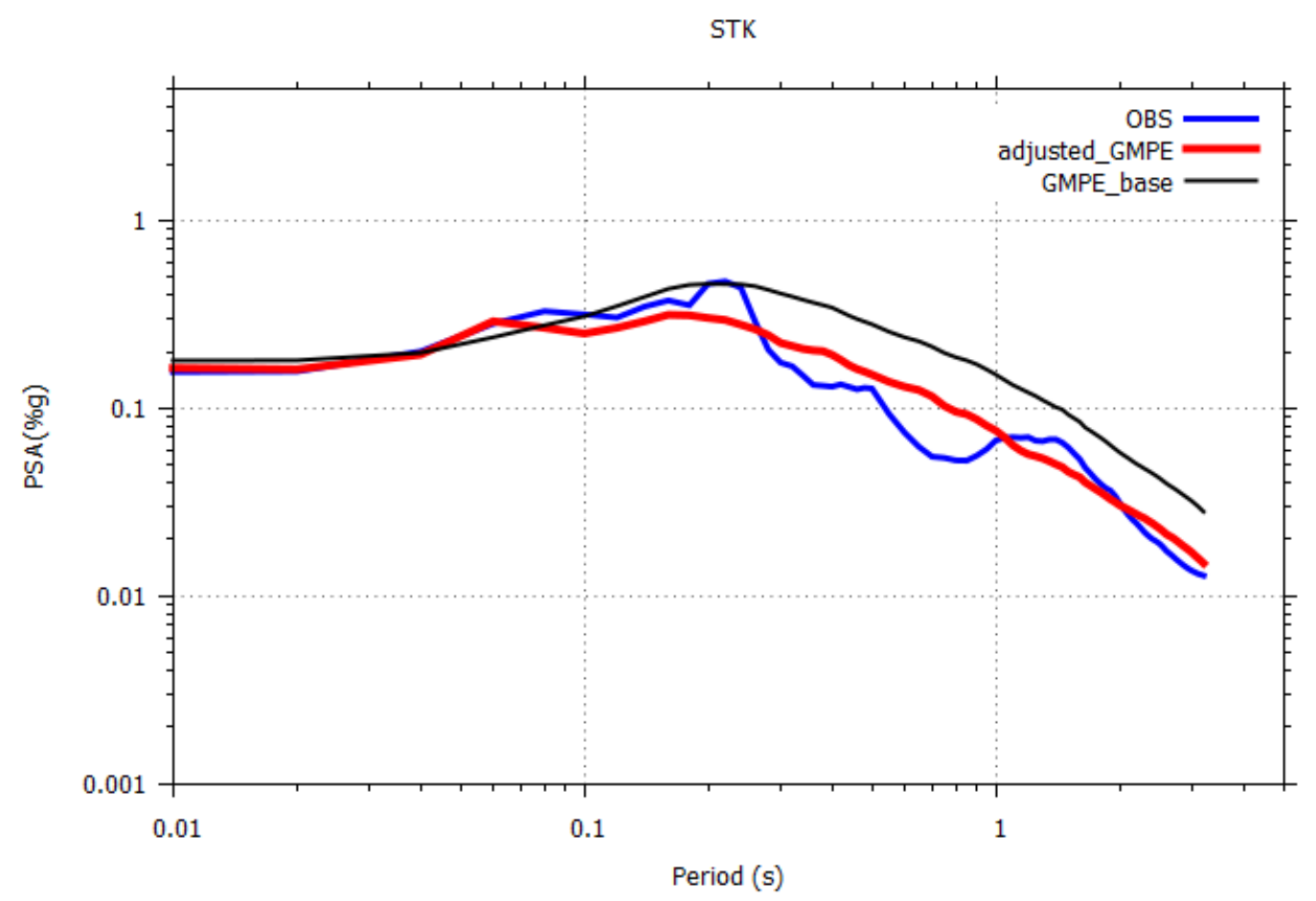

Figure 7 Comparison of the observed (OBS) and predicted (GMPE_adjusted) surface ground motion of the $2003 \mathrm{M}$ 6.8 Boumerdes earthquake. 


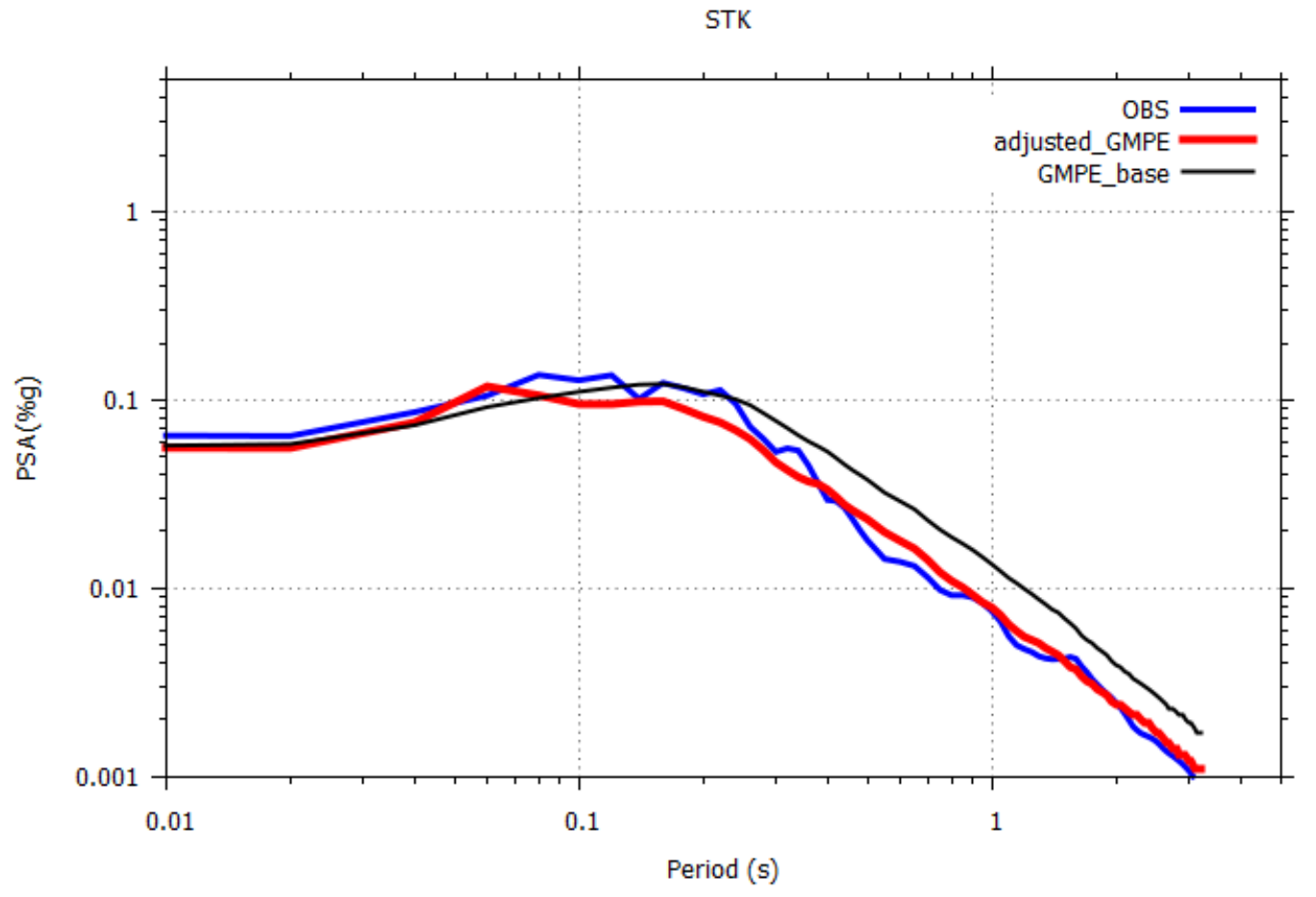

Figure 8 Comparison of the observed (OBS) and predicted (GMPE_adjusted) surface ground motion of the $2013 \mathrm{M}$ 5.4 Algiers earthquake.

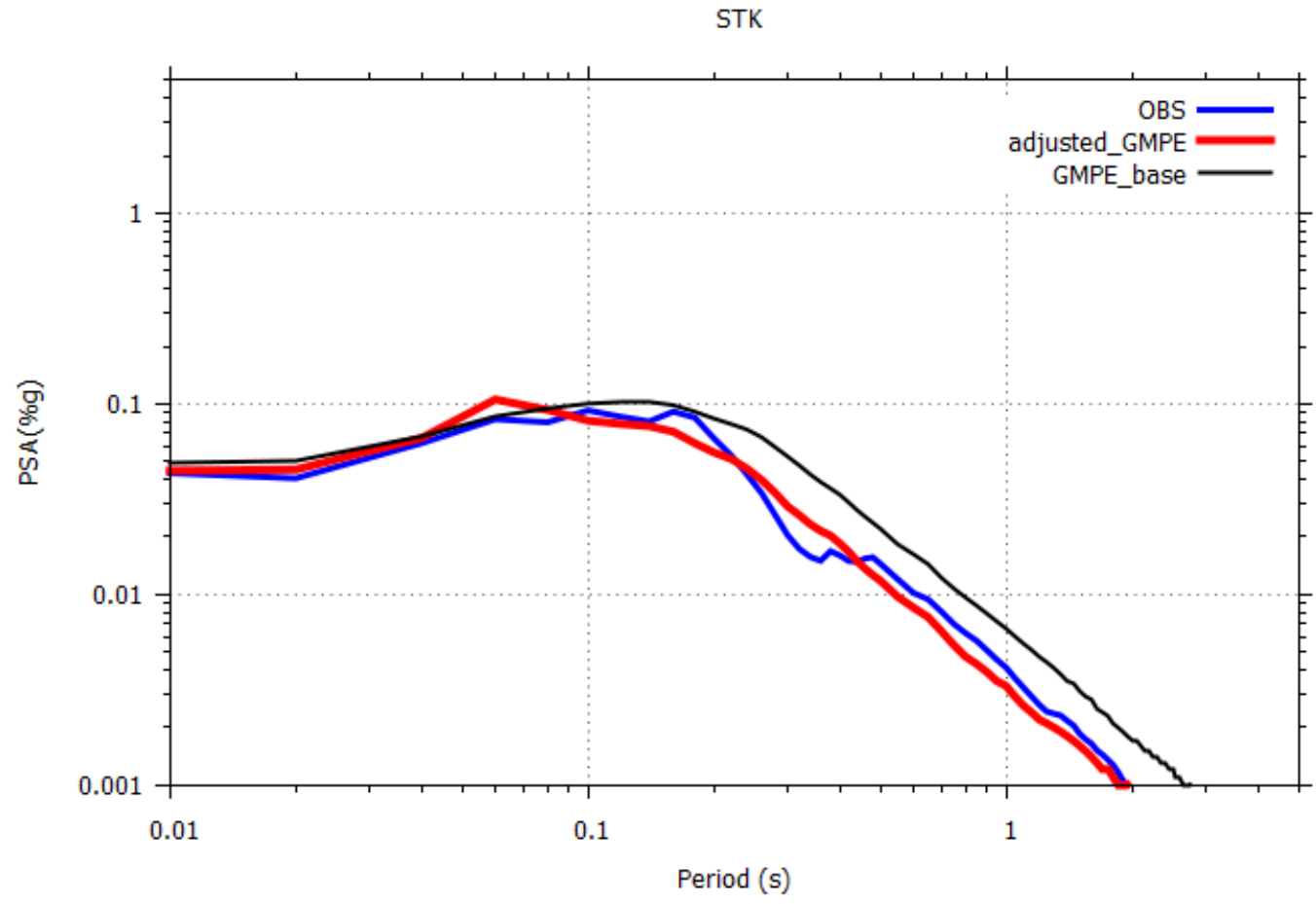

Figure 9 Comparison of the observed (OBS) and predicted (GMPE_adjusted) surface ground motion of the $2004 \mathrm{M}$ 4.7 Boumerdes EQ (aftershock). 


\section{Conclusion}

Empirical amplification function is derived for a reference site located near Kaddera dam in the region of Boumerdes using the 5\% spectral ratio between strong motion records of shallow earthquakes of magnitude Mw 4-6.8 and the corresponding rock predicted motions considering two bedrock shear wave velocity, $800 \mathrm{~m} / \mathrm{s}$ and $2500 \mathrm{~m} / \mathrm{s}$. A local ground motion prediction equation is selected (Laouami et al. 2018) together with a global earthquake model of Boore et al. (2014). Our result is also compared to the HVSR Ambient vibration curve showing a good agreement in terms of fundamental frequency $\left(f_{0}>10 \mathrm{~Hz}\right)$ and curve tendency.

Amplification factor obtained with respect to $800 \mathrm{~m} / \mathrm{s}$ shear wave velocity of the bedrock is about unity in short period $(\mathrm{T}<0.1 \mathrm{~s})$, however, a de-amplification is obtained for periods $\mathrm{T}>0.2 \mathrm{~s}$ which is in good agreement with geomorphological formation of this mountain region having a hard rock formation in depth layer with shear wave velocity that exceed largely $800 \mathrm{~m} / \mathrm{s}$. Empirical method based on strong motion records applied here for a reference site could be generalized therefore to other sites in Algeria using local strong motion data. It has the benefit to overcome limitations related to 1D linear equivalent method largely used in site specific problems.

In addition, the local GMPE is adjusted with respect to local site effect derived in this study and we found that the predicted ground motion is clearly improved in periods $T>0.1 \mathrm{~s}$ with respect to the original GMPE with Vs $30=800$ $\mathrm{m} / \mathrm{s}$. Those results are the first step toward the integration of empirical amplification function in partially non ergodic site specific PSHA application in Algeria. 


\section{References}

Anastasiadis A, \& Riga E (2014). Site classification and spectral amplification for seismic code provisions. In Earthquake Geotechnical Engineering Design (pp. 23-72). Springer, Cham.

Atik LA, Abrahamson N, Bommer JJ, Scherbaum F, Cotton F, \& Kuehn N (2010). The variability of ground-motion prediction models and its components. Seismological Research Letters, 81(5), 794-801.

Atkinson GM (2006). Single-station sigma, Bull. Seismol. Soc. Am. 96, no. 2, 446-455.

Atkinson GM (2015). Ground-motion prediction equation for small-to-moderate events at short hypocentral distances, with application to induced-seismicity hazards. Bulletin of the Seismological Society of America, 105(2A), 981-992.

Baltay AS, Hanks TC, \& Abrahamson NA (2017). Uncertainty, variability, and earthquake physics in ground-motion prediction equations. Bulletin of the Seismological Society of America, 107(4), 1754-1772.

Benfedda A, Abbes K, Bouziane D, Bouhadad Y, Slimani A, Larbes S, ... \& Bezzeghoud M (2017). The August 1st, 2014 (M w 5.3) moderate earthquake: evidence for an active thrust fault in the Bay of Algiers (Algeria). Pure and Applied Geophysics, 174(3), 1503-1511.

Boore DM, Stewart JP, Seyhan E, Atkinson GM (2014) NGA-West2 equations for predicting PGA, PGV, and 5\%-damped PSA for shallow crustal earthquakes. Earthq Spectra 30:1057-1085

Bounif A et al. (2004), The 21 May 2003 Zemmouri (Algeria) earthquake Mw 6.8: Relocation and aftershock sequence analysis, Geophys. Res. Lett., 31, L19606, doi:10.1029/2004GL020586.

Borcherdt RD, \& Glassmoyer G (1994). THE LOMA PRIETA, CALIFORNIA, EARTHQUAKE OF OCTOBER 17, 1989: STRONG GROUND MOTION AND GROUND FAILURE. US Geological Survey Professional Paper, 77.

Ibrahim R, Si H, Koketsu K, \& Miyake H (2014). Empirical Spectral Acceleration Amplification in the Iwate-Miyagi and Niigata Regions, Japan, Inferred by a Spectral Ratio Method Using GroundMotion Prediction Equations. Bulletin of the Seismological Society of America, 104(3), 14101429.

Jica, (2006) A Study of Seismic Microzoning of the Wilaya of Algiers in the People's Democratic Republic of Algeria. https://openjicareport.jica.go.jp/553/553_401.html

Khelif MF, Yelles-Chaouche A, Benaissa Z, Semmane F, Beldjoudi H, Haned A, Kherroubi A (2018). The 2016 Mihoub (north-central Algeria) earthquake sequence: seismological and tectonic aspects. Tectonophysics, 736, 62-74. 
Laouami N, Slimani A, Larbes S (2018). Ground motion prediction equations for Algeria and surrounding region using site classification based $\mathrm{H} / \mathrm{V}$ spectral ratio. Bulletin of Earthquake Engineering, 16(7), 2653-2684.

Rami Ibrahim, Hongjun Si, Kazuki Koketsu, Hiroe Miyake; Empirical Spectral Acceleration Amplification in the Iwate-Miyagi and Niigata Regions, Japan, Inferred by a Spectral Ratio Method Using Ground-Motion Prediction Equations. Bulletin of the Seismological Society of America 2014;; 104 (3): 1410-1429. doi: https://doi.org/10.1785/0120130124

Rodriguez-Marek A, Rathje EM, Bommer JJ, Scherbaum F and Stafford PJ (2014) Application of singlestation sigma and site response characterization in a probabilistic seismic hazard analysis for a new nuclear site, Bull. Seismol. Soc. Am, 104, 1601-1619.

Sahakian V, Baltay A, Hanks T, Buehler J, Vernon F, Kilb D, Abrahamson N (2018). Decomposing Leftovers: Event, Path, and Site Residuals for a Small-Magnitude Anza Region GMPE. Bulletin of the Seismological Society of America, 108(5A), 2478-2492.

Si H, Tsutsumi H, \& Midorikawa S (2010). Evaluation of hanging wall effects on ground motion attenuation relationship correcting the site effects. Proceedings of the 9 thNC

Stewart JP, Afshari K and Goulet CA (2017). Non-ergodic site response in seismic hazard analysis. Earthquake Spectra, 33(4), 1385-1414.

Stewart JP, Afshari K and Hashash YM. A 2014 Guidelines for performing hazard-consistent one-937 dimensional ground response analysis for ground motion prediction, PEER Report No. 2014/16, 938 Pacific Earthquake Engineering Research Center, UC Berkeley, C

Stewart JP, Liu A H, Choi Y (2003). Amplification factors for spectral acceleration in tectonically active regions, Bull. Seism. Soc. Am. 93: 332-352.

Stewart JP, Wang P, Teague DP, and Vecchietti A (2019, July). Applications of non-ergodic site response in ground motion modeling. In Earthquake Geotechnical Engineering for Protection and Development of Environment and Constructions: Proceedings of the 7th International Conference on Earthquake Geotechnical Engineering,(ICEGE 2019), June 17-20, 2019, Rome, Italy (p. 51). CRC Press.

Vecchietti A, Stewart JP, Cecconi M, Pane V \& Russo G (2019). Non-ergodic site response model based on local recordings for Menta Dam site.

Yelles-Chaouche AK, Haned A, Aidi C, Beldjoudi H, Kherroubi A, Semmane F \& Belheouane A. (2017). The M w 5.0 Hammam Melouane Earthquake (North Central Algeria) of 17 July 2013 in the Context of the Tellian Atlas Seismicity. Pure and Applied Geophysics, 174(4), 1601-1614. 